\title{
ОТ «ПРАВА НАЦИИ" К «ПРАВУ ПЛЕМЕНИ", ИЛИ ТРАНСФОРМАЦИЯ ПОСТСОВЕТСКОЙ ЛЕГИТИМНОСТИ В РЕСПУБЛИКАХ ДАЛЬНЕГО ВОСТОКА РОССИИ ${ }^{1}$
}

\author{
А.В. Михалев
}

(mihalew80@mail.ru)

Бурятский госуниверситет им. Д. Банзарова,

Улан-Удэ, Россия

Цитирование: Михалев А.В. От «права нации» к «праву племени», или Трансформация постсоветской легитимности в республиках Дальнего Востока России // Власть и элиты. 2021. Т. 8, № 1. С. 184-197.

DOI: https://doi.org/10.31119/pe.2021.8.1.8

Аннотация. Предпинята попытка проследить трансформацию легитимности в двух дальневосточных республиках современной России. В иентре исследовательского внимания Республика Саха (Якутия) и Республика Бурятия (бъвшие ЯАССР и БАССР) - два субъекта Российской Федерачии в составе Дальневосточного федерального округа. Основной контекст исследования - кланово-трайбалистский формат политического воображения в изучаемом регионе, пришедший на смену национальному дискурсу советского периода. В представленном исследовании речь идет лишь о дискурсе, обеспечивающем легитимность, а также о модели политического воображения, сбормировавщейся в условиях постсоветских трансформаций в азиатской части России.

Ключевые слова: ретрайбализаиия, Дальний Восток, кланы, племена, идентичность, власть, ресурсы.

${ }^{1}$ Исследование выполнено при финансовой поддержке РФФИ в рамках научного проекта № 20-011-00081. 
В представленной работе анализируется развитие политических идей, благодаря которым актуальными становятся родоплеменные идентичности. Эти идеи существуют в публичном пространстве пока еще не совсем упорядоченно, но со временем способны оформиться в доктрину. В центре внимания - одна из форм политического воображения, объясняющая легитимность власти в категориях родоплеменного дискурса. Для того чтобы более полно раскрыть специфику изучаемого явления, был выбран компаративный метод. В рамках этого метода предпринимается попытка сравнить роль ретрайбализации политического воображения в двух субъектах РФ, имеющих сходные траектории развития национальной государственности. Таким образом, в центре исследовательского внимания находятся республики Саха (Якутия) и Бурятия - два субъекта Российской Федерации в составе Дальневосточного федерального округа. Они возникли в 1922 г. (Якутская Автономная ССР) и 1923 г. (Бурят-Монгольская Автономная ССР) и тогда же вошли в состав РСФСР.

Основным контекстом исследования стал кланово-трайбалистский формат политического воображения, формирующий коллективные представления о (не)легитимности политического режима. В теоретическом плане мы в большей степени склоняемся к пониманию легитимности в духе неовеберианской концепции Дэвида Битэма. Битэм подробно разработал «нормативную структуру» легитимности, при этом четко разграничив ее и понятие легальности [Beetham 1991]. Один из первых и важнейших его тезисов заключается в том, что власть соответствует принятым/установленным в обществе правилам. В модели Битэма большое значение имеют общие убеждения управляющих и управляемых, конвенционально разделяющих веру в существующие правила, а также наличие выраженного согласия со сложившимся положением вещей. Под трайбализмом мы понимаем набор политических идей, согласно которым родоплеменные группы являются источником государственной власти и наиболее приемлемой формой идентичности.

Структура эмпирического материла исследования представляет собой сочетание четырех крупных блоков.

Первый блок - тексты, формирующие и упорядочивающие политическое воображение на региональном уровне. Речь прежде всего идет о материалах «новых» и «старых» средств массовой информации. Именно они описывают политические отношения в кланово-трайбалистских категориях, формируют соответствующую историческую мифологию 
и политический словарь. Материалы были проанализированы за последние 15 лет. Выбор хронологических рамок обусловлен тем, что на это время приходится самая высокая частота упоминаний кланов, племен, землячеств и тому подобных терминов. Идеологическая направленность отбиравшихся изданий принципиального значения не имела, вне выборки оказались лишь официальные издания, публикующие нормативные документы.

Второй блок - решения политического характера, принятые родоплеменными съездами и конференциями. Многие из них опубликованы в материалах по итогам проведения этих мероприятий. В центре внимания не только источники, относящиеся не только к бурятским и якутским объединениям, но к ряду русских старожильческих сообществ (в частности, семейских). Необходимо уточнить, что, несмотря на достаточно большую выборку, не все конференции и съезды выносили решения трайбалистской политической направленности. Однако в выборку попал очень большой объем контента.

Третий блок - работы профессиональных этнологов, антропологов и этнополитологов, обосновывавших на волне национально-культурного возрождения в 1990-е годы родоплеменные границы местного сообщества. Эти тексты, несмотря на достаточно ограниченный круг читателей и низкие тиражи, редко превышающие 300-500 экземпляров, все же оказали влияние на медийный дискурс. В условиях образовавшегося в постсоветский период идеологического вакуума региональные гуманитарии обеспечили условия для нового прочтения общественнополитических процессов. Сюда же относятся работы ученых, выступающих с критикой неотрайбализма и описания политики в категориях межклановой борьбы. Данный нарратив сформировался в процессе дебатов на страницах средств массовой информации в 2010-е годы.

\section{ПОЛИТИЧЕСКИЙ КЛАН В РЕГИОНАЛЬНОМ КОНТЕКСТЕ}

Политический клан - достаточно распространенное в современном политическом дискурсе понятие. Его часто связывают с концепциями периферийного и кланового капитализма [Kosals 2007]. Под политическим кланом принято понимать сплоченные группы, организованные на основе деловых и неформальных интересов и претендующие на властные ресурсы. В ряде случаев политический клан понимается как доклас- 
совый институт, адаптировавшийся к современным условиям [Ламажаа 2008]. Однако, по мнению Л. Косалса, в российских условиях это одно из проявлений «crony capitalism» [Kosals 2007]. В итоге сложилась ситуация множественности интерпретаций этого термина в политическом контексте, а какая-либо конвенциональная рамка на данный момент отсутствует.

В изучаемых нами республиках Дальнего Востока понимание клана в публичной сфере тяготеет ближе к традиции, интерпретирующей его как традиционный доклассовый институт. Речь идет о публичной сфеpe, стремящейся легитимировать неформальные политические отношения с опорой на неотрадиционалистское воображение. В этих условиях клан становится или группой земляков, связанных на основе «Blut und Boden», или еще более сложной родоплеменной группой, объединенной реальным или мифическим родством. При этом за пределами Бурятии и Якутии понятие клан приобретает более современное содержание, связанное с неформальной солидарностью и теневой борьбой за ресурсы.

Таким образом, в двух дальневосточных республиках мы фиксируем ретрайбализацию постсоветских клановых отношений. Ретрайбализация понимается нами в рамках дефиниции М. Маклюэна, определившего ее как процесс объединения людей в новом состоянии множественных племенных существований [Маклюэн 2003: 153]. Это формирует новую медийную политическую реальность, в которой территориальные группы, присвоившие себе право называть себя именами древних племен кочевой Азии, противостоят друг другу в борьбе за ресурсы.

В этой ситуации мы сталкиваемся с кризисом доверия к институтам модерна, будь то национальное государство или демократия, и с апелляцией к доклассовым формам солидарности, что позволяет говорить о формировании нового способа легитимации власти. Мы констатируем возникновение общественных правил и норм, посредством которых допустимо, или же напротив неприемлемо, интерпретировать политические отношения. Это напрямую отсылает нас к концепции легитимности Д. Битэма, писавшего о том, что она опирается на нормативную структуру [Beetham 1991]. Такая структура предполагает границы политического воображения в так называемых национальных республиках, а также словарь, позволяющий говорить о региональной элите негативно или позитивно, но строго в контексте ретрайбализации. 
Специфика ретрайбализации на Дальнем Востоке России предполагает возвращение в общественно-политический лексикон категорий времен реформы М.М. Сперанского - роды, племена, родовые лидеры. В связи с этим ключевым текстом для нашего исследования является работа М.М. Ковалевского, подробно описавшего кланы Северной Азии [Ковалевский 2002], а изучаемые нами республики в дореволюционной традиции относили к Северной Азии. Необходимо отметить, что именно социолог Ковалевский заложил основу понимания политических отношений в Северной Азии через родоплеменные отношения. В его работах начала XX в. предприняты первые попытки сравнения местной ситуации с Кавказом [Ковалевский 2002]. В XXI в. это знание, наряду с материалами имперской этнографии, стало вновь актуальным и начало определять способ интерпретации политических процессов.

Наиболее наглядный пример в Бурятии - описание регионального политического процесса в СМИ через призму противостояния «западных» и «восточных» бурятских кланов, восходящих к племенам древности. В случае Якутии речь идет о соперничестве земляческих групп (улусов), объединенных территориальной идентичностью. Важным становится фактор исключения кланов из числа формальных политических институтов. При этом в обеих изучаемых нами республиках на официальном уровне отрицается значимость кланов в политике. Как отметил экс-президент республики Саха Михаил Николаев в интервью изданию «Коммерсантъ», «у клана должен быть родоначальник - богатый, плодовитый, а в Якутии всегда была борьба за выживание - как бы перезимовать. Не было тут и каменных строений, которые можно было бы передать по наследству, не было накопления капитала. Природа не допускала щедрости, хозяйство было только для пропитания» [Перцев 2018].

В целом, говоря о кланах в политической сфере Бурятии и Саха, мы может однозначно констатировать их неформальный характер. Политическая элита не готова открыто признавать клановый характер отношений в силу как юридических, так и политических причин. Однако на уровне СМИ о кланах и о ретрайбализации принято писать открыто, формируя особый способ интерпретации политики, позволяющий подчеркнуть роль традиций и сохранить национально-конфессиональный баланс. Во многом клановый дискурс становится латентной формой национализма, позволяющей исключать одних и легитимизировать власть других. Так, в Бурятии мы можем зафиксировать упоми- 
нания западных и восточных бурятских кланов [Zhanaev 2019: 71-80], а также семейского клана (потомков русских старообрядцев), за которыми неформально «закреплены» три района республики [Белькова 2018; Галиндабаева, Карбаинов 2020], хотя в Бурятии, как и в Саха, существует официальная позиция, согласно которой кланы там отсутствуют. Однако, в отличие от Якутии, это точка зрения вызывает в Бурятии ожесточенные дискуссии.

\section{А ПОЧЕМУ НЕ НАЦИОНАЛИЗМ?}

Идея национально-государственных образований (республик) в составе РСФСР во многом опиралась на ленинскую идею о праве наций на самоопределение. В начале 1990-х годов в ходе «парада суверенитетов» местные элиты стали заявлять о праве на суверенитет и формировать самостоятельные органы политического управления, в том числе национальные партии. Так, в 1990-е годы в Бурятии были созданы местные политические объединения «Бурят-монгольская народная партия», движение «Нэгэдэл». В Саха подобными объединениями стали «Саха кэскилэ» и «Саха омук». Они были первыми общенациональными политическими институтами постсоветского периода. Характеризуя этот период, нельзя не согласиться с А. Ливеном, утверждающим: «В современном мире величайшим и наиболее долговечным источником этих чувств и легитимности государства является национализм. За исключением коммунизма в течение его непродолжительного революционного периода, ничто в современной истории не может сравниться с национализмом в качестве источника коллективных действий, добровольных жертв и, конечно, государственного строительства» [Ливен 2020: 26].

Однако со временем активность национальных объединений существенно снизилась. Кроме того, на федеральном уровне было принято несколько изменений в закон «О политических партиях» (2001 и 2004 гг.), после которых региональные политические партии потеряли возможность для развития. В итоге национальные элиты в субъектах Российской Федерации получили импульс для работы в рамках отделений общефедеральных партий. Параллельно с этим происходила трансформация местных национализмов, которые стремительно теряли популярность. Обретение суверенитета, пусть даже номинального, сочеталось с ростом бедности и депривации, а вслед за этим приходило и разочарование в национальной идее. В условиях борьбы за выживание 
на первый план начали выходить религиозные институты и локальные территориальные солидарности.

Большое значение для процессов родоплеменной консолидации элит имеет возрождение шаманизма, получившего статус традиционной религии [Указ Президента 1996]. Общеродовые обряды обеспечили широкий интерес к генеалогии и актуализировали родоплеменные идентичности. Важным контекстом происходящего стал процесс рурализации городского пространства столиц изучаемых республик. Вслед за этим возник феномен городского шаманизма. Начиная с 1991 г. активным участником политических процессов становится буддистское духовенство. В 2010-е годы оно постепенно перенимает родоплеменную повестку у шаманов. Так, в 2017 г., приветствуя нового главу Бурятии, духовный лидер буддистов (хамбо-лама) заявил: «Вот смотрите - есть пять основных бурятских племен: селенгинский, хонгодоры, хори, эхириты и булагаты. У меня представлены все пять, у вас тоже должно быть пять» [Амбатова 2017].

В свою очередь, в 2018 г. глава Якутии Айсен Николаев заявил: «Я не делю людей по кланам. Подход у меня простой: если ты компетентен, ты работаешь, нет - уходи. И будь ты хоть тысячу раз уважаемым в каком-либо клане...» [Национальность в Якутии 2018]. De facto глава признал существование в республике кланов, однако отозвался о них в негативном ключе. То есть в данной ситуации в Саха все еще остается значимой национальная идентичность и основанная на ней идея политического представительства. Хотя муниципальные выборы 2020 г. в этом субъекте на уровне федеральных СМИ были охарактеризованы как борьба кланов: «В районных выборах, на муниципальном уровне, где выбирали глав, депутатов - большую роль играет фактор личного знакомства с кандидатом, национальный фактор, семейственность. К примеру, населенный пункт с 10 тыс. населения, где практически каждый знает друг друга, выборы - это борьба семейных кланов» [Выборы в Якутии 2020].

Однако национализм как идеология никуда не исчез, он скорее отошел на второй план общественно-политической повестки. Идея общей солидарности еще актуальна в среде академической и культурной элиты, особенно в преддверии столетий с момента образования республик. При этом ретрайбализация начинает постепенно оттеснять на периферию дискурс национального единства, выводя на первый план неравномерность распределения ресурсов между различными группами элиты. 
Вместе с тем видится справедливым замечания Маршала Маклюэна о том, что электронные СМИ актуализировали потребность в знаковости и привели к ретрайбализации. Этот тезис хорошо иллюстрируется нашими эмпирическими данными, в частности в случае Бурятии гегемония трайбалистского дискурса абсолютно синхронно распространению не электронных (по Маклюэну), а уже цифровых массмедиа. Более того, среда, в которой воспроизводятся трайбалистские тексты и нарративы, также относится к числу «новых массмедиа».

\section{ЛЕГИТИМНО ЛИ ПРАВО ПЛЕМЕНИ НА САМООПРЕДЕЛЕНИЕ?}

Проблема политического представительства родоплеменных групп не являлась актуальной вплоть до 2010-х годов. Она предполагает претензии на присутствие не только в выборных органах власти, но и в органах исполнительной власти. Речь идет о смыслообразованиях, отличающихся по характеру своей знаковости от иных способов интерпретации политики. В качестве коллективного «Другого» в данной ситуации выступает административно-бюрократическая система координат с многочисленными запутанными внутренними лояльностями и идентичностями. Тенденция к распространению данной модели проявила себя только в Бурятии, что свидетельствует о более высоком уровне ретрайбализации здесь, чем в Саха.

Публичная манифестация трайбалистских претензий на политическое представительство четко локализована в границах родоплеменных институций: съездов, конференций, праздников. В этом контексте заявления для публичной сферы, тем более манифестации, не являются нормативными. Однако в феврале 2018 г. на страницах газеты «Угайм зам» было опубликовано заявление съезда одной из родственно-территориальных групп Бурятии: «Поступило предложение при следующей переписи населения в графе национальность у бурят указывать и племенную принадлежность, а также при выборах депутатов в Народный Хурал выдвигать не только по партийным спискам и территориям, но чтоб и племена могли составлять списки своих кандидатов в депутаты. Обсуждался вопрос о необходимости образования независимого Совета старейшин из представителей племен по 3 человека от каждого из них» [Башитов 2018: 2].

Идея получила более широкое распространение, став основой переосмысления принципа организации республики, постулируя тезис о том, 
что многочисленные кланы - это основа демократического развития: «В общем, несмотря ни на что, Бурятия движется к республиканской форме правления, где Народный Хурал (парламент Бурятии. - A.M.) будет играть основополагающую роль. И главным фактором достижения этого блага могут оказаться кланы! Такая форма правления, видимо, больше подходит Бурятии и по духу, и по сути. В ней будет много идей и споров. А в споре, как говорил Платон, рождается истина» [Очиров 2017].

Наряду с этим начался процесс сакрализации истории родоплеменных групп, напрямую ассоциирующихся с политическими кланами. Активное издание фольклорных материалов стало приобретать вполне определенное политическое значение: «Мифы и легенды о происхождении монгольских племен и кланов могли возникнуть в период, когда рушилась племенная система древних народов. Некоторые мифы говорят о небесном происхождении их государств и племен. Есть много интересных легенд монгольских народов, которые мы можем найти в исторических источниках, а также в устных сказках. Например, “Легенда Хорь Түмэд, Хоридой мэргэн”, “Легенда Эргүнэ хун”, “Четыре Ойрата”, “Мянгаты”, “Сартуулы”, “Элеты или Өөлд”, “Торгуты” и “Үзэмчины” и т. д.» [Майдар 2018].

Эти процессы отражают интересы определенной части региональной элиты, которая видит в клановом формате республиканизма норму, которую осталось лишь закрепить конституционно. Идея парламентской республики на основе кланового представительства отражает интересы сугубо местных (укорененных) элитных групп, откровенно исключая сделавших карьеру на стройках БАМа или назначаемых/согласованных из Москвы руководителей региональных отделений партий. Клановая форма республики в понимании идеологов ретрайбализации в политике должна лишь закрепить существующий status quo: «Трагедией бурятского общества является то, что у нас элита, в прямом ее понимании, не сформировалась и правят обществом и в политике, и в экономике не элиты, а группы людей, к которым наиболее применимы такие понятия, как “кланы” и “каста”. Но вполне может быть, что это всего лишь следующий виток развития бурятского общества» [Очиров 2017].

В этой ситуации представляет интерес и позиция лидера Буддистской традиционной Сангхи России хамбо-ламы Д. Аюшеева. Духовный лидер выступает за сохранение культурных различий между сложив- 
шимися родоплеменными группами, отмечая большое значение диалектов бурятского языка. Так, в 2019 г. он сделал пост на своей странице в «Фейсбуке» (орфография и пунктуация авторы сохранены): «Почему буряты из Кяхты только 11 \% и буряты из Селенги лишь 15 \% говорят на родных языках. Ответ прост они физиологически, как 7 млн монголов, не могут выговорить букву h. Таким образом для них были закрыты двери во все культурные и руководящие учреждения Улан Удэ. Есть ли в мире методика, чтобы 7 млн монголов заставить говорить наше великое литературное h? Ответ - нет. Вот потому то надо выпускать газету Бүриад Үнэн на селенгинских языках» [Аюшеев 2019].

Исторически сложившееся и поддерживаемое по сей день существование культурных и лингвистических границ обеспечивает основу для проведения пограничной линии и внутри политической элиты. Однако данный процесс экстраполируется и на электорат, предполагая формулу «Голосуй за своего» (предвыборный лозунг думской кампании 2016 г.). Трайбалистская ревизия идеи представительства открывает и новые перспективы для легитимизации выборов с низкой явкой. Строго ограничивая группу, «имеющую право» на власть, русскими старожилами и бурятами, сторонники трайбализации создают новую модель справедливости в вопросе распределения ресурсов. Однако подобная реакция вызвана сломом локальности в ходе развития глобальных проектов. Одним из таких примеров является попытка включения Бурятии в китайский логистический проект «Степной путь», а также планы по строительству газопровода через ее территорию.

\section{ЗАКЛЮЧЕНИЕ}

В рамках статьи мы попытались проследить то, каким образом процесс ретрайбализации все больше захватывает республики Дальнего Востока. Несомненно, что этот феномен является частью глобальных процессов, развернувшихся в мире. Ретрайбализация привела к возникновению новой легитимности, основанной на праве клана или племени на политические ресурсы на территории, с которой оно исторически или мифологически связано. Такая легитимность опирается на нормативную структуру, возникшую благодаря новым нормам, разделяемым населением изучаемых субъектов РФ. Однако за пределами представлений о легитимности остается Realpolitik с совершенно иными принципами взаимоотношений внутри элитных групп. 
Процесс ретрайбализации позволяет выявить контрасты в политическом развитии двух дальневосточных субъектов. Если сто лет назад обе республики имели схожие условия для развития, то в XXI в. эти тенденции почти нивелировались в ходе постсоветских преобразований. В таких условиях динамика ретрайбализации в политической сфере Бурятии прослеживается достаточно четко, в то время как в Саха она фиксируются слабо.

Изученные нами кланы - это продукт политического воображения, в основу которого легли материалы этнографии и социологии времен империи. Ответ на закономерный вопрос о том, кем воображаются эти группы, все же не столь очевиден, как может показаться. Этноактивисты и журналисты - всего лишь та часть, которая непосредственно вовлечена в массовую трансляцию новых смыслов. Однако их производство оказывается за пределами внимания большинства исследователей. На наш взгляд, большую роль в этом процессе сыграли деятели «культурного возрождения» конца 1980-х - середины 1990-х годов. Именно тогда были заложены основы, на которые опирается вся конструкция современной ретрайбализации.

Таким образом, нормативная структура ретрайбалистской легитимности укоренялась на протяжении последних тридцати лет. Влияние глобальных культурных трендов, таких как медиевализм, сыграло роль акселератора. В итоге к 2020 г. оформились экзотические идеи «кланового представительства», в корне переформатирующие устоявшуюся модель республиканизма. В сущности, в ходе постсоветских трансформаций идея «национальной республики», сформулированная для Бурятии и Якутии в период «парада суверенитетов», меняется, теряя общие черты под влиянием целого ряда глобальных факторов.

\section{Литература}

Белькова А.А. «Семейский клан» в постсоветской Бурятии: приватизация идентичности в политике // Политическая наука. 2018. № 2. С. 195-213.

Галиндабаева В., Карбаинов Н. Карымы и семейские в Бурятии: трансформации этнического фронтира // Ab Imperio. 2020. № 3. С. 115-156.

Ковалевский М.М. Клан у аборигенных племен России // Социологические исследования. 2002. № 5. С. 129-138.

Ламажаа Ч.К. «Клан»: понятие в социальных науках // Гуманитарные науки: теория и методология. 2008. № 2. С. 121-131.

Ливен А. Прогрессивный национализм // Россия в глобальной политике. 2020. № 5 (105). C. $25-42$ 
Маклюэн Г.М. Понимание медиа: внешние расширения человека. М.: Кучково поле, 2003. 464 с.

Beetham D. The Legitimation of Power (Issues in Political Theory). London: Macmillan Education UK, 1991. 267 p.

Kosals L. Essay on Clan Capitalism in Russia // Acta Oeconomica. 2007. Vol. 57, № 1. P. 67-85.

Zhanaev A. The Human Being in Social and Cosmic Orders. Categories of Traditional Culture and the Problems of Contemporary Buryat Identity. Poznan: Wydawnictwo Naukowe UAM, 2019. 270 p.

\section{Источники}

«Национальность в Якутии преимуществ не дает» [Беседа с Айсеном Николаевым]. // ИА Федерал Пресс. 14.09.2018. URL: https:/glava.sakha.gov.ru/news/ front/view/id/2941486 (дата обращения: 06.11.2021).

Амбатова С. Хамбо-лама рассказал Алексею Цыденову о пяти основных бурятских племенах. // Московский комсомолец в Бурятии. 15.02.2017. URL: https://ulan.mk.ru/articles/2017/02/15/khambolama-rasskazal-alekseyu-cydenovuo-pyati-osnovnykh-buryatskikh-plemenakh.html (дата обращения: 06.11.2021).

Аюшеев Д. Фейсбук 18.09.2019 // URL: https://www.facebook.com/damba. ayusheev.8/posts/887528704965973 (дата обращения: 06.11.2021).

Башитов А.Д. Конференция Булагатов // Угайм Зам. 2018. № 47.

Выборы в Якутии - это борьба семейных кланов: эксперт // ИA Regnum. 14.09.2020. URL: https://regnum.ru/news/polit/3062107.html (дата обращения: 06.011.2021).

Майдар С. Потрясающая монгольская легенда о происхождении бурятских родов. 28.04.2018 // Asia-Russia Daily. URL: https://asiarussia.ru/blogs/19539/ (дата обращения: 06.11.2021).

Очиров Б. Академику Базарову: в Бурятии кланы есть и их немало. 18.09.2017 // Asia-Russia Daily. URL: https://asiarussia.ru/blogs/17665/ (дата обращения: 06.011.2021).

Периев А. «Мы выжили там, где вымерли мамонты». Как национальный вопрос повлиял на смену власти в Якутии // Коммерсантъ. 13.10.2018. URL: https://www.kommersant.ru/doc/3766947 (дата обращения: 06.11.2021).

Указ Президента Республики Бурятия от 21 мая 1996 г. № 183 «О Концепции государственно-церковных отношений в Республике Бурятия» (1996) // Электронный фонд правовых и нормативно-технических документов. URL: https:/docs.cntd.ru/document/473803216/titles/1OKOC2L (дата обращения: 13.07.2021). 


\title{
FROM THE “RIGHT OF NATION” TO THE "RIGHT OF TRIBE", OR TRANSFORMATION OF POST-SOVIET LEGITIMACY IN THE REPUBLICS OF THE FAR EAST OF RUSSIA1
}

A.V. Mikhalev

(mihalew80@mail.ru) Buryat State University,

Ulan-Ude, Russia

Citation: Mikhalev A.V. From the "right of nation" to the "right of tribe", or Transformation of post-Soviet legitimacy in the republics of the Far East of Russia. Vlast' i elity [Power and Elites], 2021, 8 (1): 184-197. (In Russian)

DOI: https://doi.org/10.31119/pe.2021.8.1.8

\begin{abstract}
In the article, we attempt to trace the transformation of legitimacy in the two Far Eastern republics of modern Russia. The Republic of Sakha (Yakutia) and Buryatia (former YaASSR and BASSR) are in the focus of research as two entities of the Russian Federation as a part of the Far Eastern Federal District. The main context of the research is the clan-tribalist format of political imagination in the studied region, which has replaced the national discourse of the Soviet period. The presented study deals only with the discourse that ensures legitimacy, as well as the model of political imagination that was formed in the context of post-Soviet transformations in the Asian part of Russia.
\end{abstract}

Keywords: retribalization, clans, Far East, tribe, identity, power, resources.

\section{References}

Beetham D. The Legitimation of Power (Issues in Political Theory). London: Macmillan Education UK, 1991. 267 p.

Bel'kova A.A. «Semejskij klan» v postsovetskoj Burjatii: privatizacija identichnosti v politike [ «Semeiskii (familialistic) clan» in post-soviet Buryatia: Privatization of identity in politics]. Politicheskaja nauka, 2018, 2, pp. 195-213. (In Russian).

Galindabaeva V., Karbainov N. The Karyms and Semeiskie in Buryatia: Transformation of the Ethnic Frontier. Ab Imperio, 2020, 3, pp. 115-156. (In Russian).

Kosals L. Essay on Clan Capitalism in Russia. Acta Oeconomica, 2007, 1 (57), pp. $67-85$.

${ }^{1}$ The article was prepared with the support of the Russian Foundation for Basic Research and the Expert Institute for Social Research, project no. 20-011-00081. 
Kovalevskij M.M. Klan u aborigennyh plemen Rossii [Clan among the aboriginal tribes of Russia]. Sociologicheskie issledovanija [Sociological research], 2002, 5, pp. 129-138. (In Russian)

Lamazhaa Ch.K. «Klan»: ponjatie v social'nyh naukah [Clan reflection in social sciences]. Gumanitarnye nauki: teorija i metodologija, 2008, 2, pp. 121-131. (In Russian).

Liven A. Progressive nationalism. Rossiya v global'noy politike [Russia in Global Affair], 2020, 5, pp. 25-42. (In Russian).

McLuhan G.M. Ponimaniye media: vneshniye rasshireniya cheloveka [Understanding Media: The Extensions of Man]. Moscow: Kyuchkovo Pole, 2003. 464 p. (In Russian).

Zhanaev A. The Human Being in Social and Cosmic Orders. Categories of Traditional Culture and the Problems of Contemporary Buryat Identity. Poznan: Wydawnictwo Naukowe UAM, 2019. 270 p. 